\title{
Determinação do perfil fitoquímico de extrato com atividade antioxidante da espécie medicinal Cordia verbenacea DC. por HPLC-DAD
}

\author{
SANTI, M.M.'; SANCHES, F.S.'; SILVA, J.F.M.'; SANTOS, P.M.L.. ${ }^{*}$ \\ Universidade Federal do Rio de Janeiro, Instituto de Química, Laboratório de Química Medicinal, Polo de \\ Xistoquímica, Rua Hélio de Almeida, 40, CEP 21941-614, Ilha da Cidade Universitária, Rio de Janeiro- Brasil \\ *paulalessa@iq.ufrj.br
}

\begin{abstract}
RESUMO: O presente trabalho teve por objetivo investigar a atividade antioxidante dos extratos das folhas de Cordia verbenacea obtido por maceração em etanol e partição em solventes orgânicos. O infuso das folhas também foi investigado. O teor de fenóis totais foi avaliado pelo método de Folin-Ciocalteau e o de flavonoides totais pela formação de complexo com cloreto de alumínio. O extrato etanólico, as subfrações e o infuso foram testados em diversas concentrações para determinar a atividade sequestradora de DPPH expressa em termos de sua $\mathrm{CE}_{50}$. A melhor atividade antioxidante encontrada foi para o extrato em acetato de etila, $E A, C E_{50} 15,0 \pm 0,5 \mu \mathrm{g} \cdot \mathrm{mL}^{-1}$. Os ensaios espectrofotométricos revelaram altas concentrações de fenóis e de flavonoides no extrato EA. A análise por HPLC-DAD foi realizada para se obter o perfil de UV-Vis dos picos cromatográficos do extrato EA. As características espectrais foram relacionadas a compostos fenólicos e flavonoídicos.
\end{abstract}

Palavras-chave: Cordia verbenacea, DPPH, fenóis, flavonoides.

ABSTRACT: Phytochemical profile determination from extracts with antioxidant activity of the medicinal species of Cordia verbenacea DC. by HPLC-DAD. The objective of the present study was to investigate the antioxidant activity of extracts from Cordia verbenacea leaves obtained by maceration in ethanol and partitioned with organic solvents. The infusion of leaves was also investigated. The total phenolic and total flavonoid content was evaluated by the Folin-Ciocalteau method and by the aluminum chloride complex method, respectively. The ethanol extract, the subfractions and the infusion were assayed at various concentrations to determine the DPPH scavenging activity expressed in terms of $\mathrm{CE}_{50}$. The best antioxidant activity was found on the ethyl acetate extract, EA, $C_{50} 15.0 \pm 0.5 \mu \mathrm{g} \cdot \mathrm{mL}^{-1}$. The spectrophotometric assays revealed high phenol and flavonoid concentrations on the EA extract. The HPLC-DAD analysis was performed to reveal the UV-Vis profile of the chromatographic peaks of the EA extract. The UV spectral characteristics were related to phenol and polyphenol compounds.

Keywords: Cordia verbenaceae, DPPH, phenols, flavonoids.

\section{INTRODUÇÃO}

A espécie Cordia verbenacea DC. (Boraginaceae), conhecida popularmente como erva-baleeira, é um arbusto ereto, muito ramificado, de 1,5 a $2,5 \mathrm{~m}$ de altura, com flores pequenas e brancas dispostas em inflorescências terminais. É nativa de quase todas as regiões do Brasil, especialmente na costa brasileira. Apresenta crescimento vigoroso e espontâneo e em alguns casos é considerada planta daninha. Na medicina popular é utilizada na forma de chá via oral, a partir das folhas, por apresentar efeito anti-inflamatório, antiartrítico, analgésico, tônico e antiulcerogênico. $O$ uso externo do chá é empregado como cicatrizante de feridas e úlceras (Lorenzi \& Matos, 2008).

Estudos desenvolvidos por Roldão et al. (2008) comprovaram a atividade antiulcerogênica do extrato etanólico das folhas, através do método de indução de lesão gástrica por etanol/ $/ \mathrm{HCl}$ e etanol, quando administrados por via oral em ratos. C. verbenacea apresentou uma potente atividade antiúlcera na dose de $125 \mathrm{mg} \cdot \mathrm{kg}^{-1}$. No mesmo trabalho, o extrato etanólico apresentou atividade antioxidante, frente à peroxidação lipídica, apresentando valor de $\mathrm{CE}_{50}$ de $76,11 \mu \mathrm{g} \cdot \mathrm{mL}^{-1}$. A atividade antiúlcera, então, foi correlacionada com a atividade antioxidante apresentada pelo extrato. Em 
trabalho realizado por Michielin et al. (2011), foram produzidos extratos das folhas de $C$. verbenacea obtidos por diferentes métodos extrativos sendo, posteriormente, submetidos a ensaios antioxidantes. Como resultado, observou-se que a atividade antioxidante foi mais potente nos extratos polares.

O presente trabalho teve como objetivo analisar o potencial antioxidante dos extratos das folhas de Cordia verbenacea frente ao radical DPPH, determinar o teor de fenóis totais e uma estimativa do teor de flavonoides dos extratos, avaliar o perfil fitoquímico do extrato mais ativo por técnicas cromatográficas e espectroscópicas e verificar uma possível correlação entre a atividade antioxidante observada e o teor de fenóis e de flavonoides.

\section{MATERIAL E MÉTODO}

\section{Material vegetal}

A espécie $C$. verbenacea foi coletada na região de Cabo Frio, RJ, em janeiro de 2010 e 2012, e autenticada pela Profa. Dra. Rosana Conrado Lopes. Uma exsicata está depositada no herbário do Instituto de Biologia da Universidade Federal do Rio de Janeiro sob o $n^{\circ}$. RFA 37990.

\section{Preparação dos extratos}

Após a coleta, as folhas foram secas à sombra por uma semana. Em seguida, as folhas secas $(150 \mathrm{~g})$ foram trituradas e submetidas à maceração estática em etanol 95\% (1 L) à temperatura ambiente por três semanas, intercalando-se uma etapa de filtragem a cada semana e remacerando-se o resíduo vegetal. A escolha do método extrativo foi baseada em estudos anteriores, cujo método apresentou o melhor rendimento para a obtenção do extrato etanólico bruto seco (Santi et al., 2010).

O extrato etanólico bruto foi concentrado sob pressão reduzida em rotavapor, fornecendo $13,59 \mathrm{~g}$ de extrato bruto seco (EE). Após a separação de 1,0 g do EE para testes, o material restante foi submetido à separação líquido/líquido em solventes de polaridade crescente, utilizando-se funil de separação. Ao extrato EE foi adicionada $250 \mathrm{~mL}$ de uma mistura etanol:água (9:1) seguindo-se da adição de três alíquotas de $100 \mathrm{~mL}$ de hexano. A fase etanólica foi separada, concentrada em rotavapor e ressuspensa em 300 $\mathrm{mL}$ água, sendo em seguida, particionada com diclorometano, acetato de etila e n-butanol. Após a concentração das fases em rotavapor obteve-se 3,57 $\mathrm{g}$ de extrato em hexano (EH), 3,7 $\mathrm{g}$ de extrato em diclorometano (ED), 0,3 $\mathrm{g}$ de extrato em acetato de etila (EA), 0,21 g de extrato em n-butanol (EB) e 1,1 $\mathrm{g}$ de resíduo aquoso (RA). Preparou-se uma infusão com $1,5 \mathrm{~g}$ de folhas secas onde foram adicionados $150 \mathrm{~mL}$ de água a $100 \mathrm{C}^{\circ}$, seguida de repouso por
$10 \mathrm{~min}$. Uma alíquota foi concentrada para testes e codificada como infusão (IN). Os solventes utilizados foram em grau analítico.

\section{Instrumental}

As medidas de absorvância foram realizadas em espectrofotômetro marca BIOSPECTRO e a análise por HPLC-DAD em cromatógrafo SHIMADZU Prominence.

\section{Determinação do teor de fenóis totais pelo método Folin-Ciocalteau \\ O teor de fenóis foi determinado pelo método} espectrofotométrico de Folin-Ciocalteau (Lugasi et al., 1998; Oliveira et al., 2009) utilizando ácido gálico como padrão. Esse reagente consiste de mistura de cor amarela dos ácidos fosfomolibídico e fosfotungstico. O molibdênio apresenta estado de oxidação $\mathrm{VI}^{+}$. $\mathrm{Na}$ presença de certos agentes redutores, como os compostos fenólicos, forma-se um complexo molibdênio-tungstênio azul, no qual a média do estado de oxidação dos metais está entre $\mathrm{V}^{+}$e $\mathrm{VI}^{+}$e cuja coloração permite a determinação da concentração das substâncias redutoras.

Os extratos secos foram diluídos em EtOH para obter soluções com concentração de $10 \mathrm{mgmL}^{-}$ 1. A uma alíquota de $0,1 \mathrm{~mL}$ de cada solução foram adicionados $7,0 \mathrm{~mL}$ de água, $0,8 \mathrm{~mL}$ do reagente de Folin-Ciocalteau (1:3 de água) e 1,2 $\mathrm{mL}$ de solução aquosa de $\mathrm{Na}_{2} \mathrm{CO}_{3}$ a $20 \%$. Após 2 horas, as absorvâncias das amostras foram medidas a $760 \mathrm{~nm}$. Como referência, foi obtida uma curva analítica com o ácido gálico, que forneceu a equação da reta para a conversão da absorvância medida em miligramas equivalentes de ácido gálico por grama de extrato $\left(m g E A G . g^{-1}\right)$.

\section{Estimativa do teor de flavonoides totais pela complexação com $\mathrm{AlCl}_{3}$ $\mathrm{O}$ teor de flavonoides totais foi estimado} espectrofotometricamente pela reação com $\mathrm{AlCl}_{3}$, utilizando quercetina como padrão (Dowld, 1959; Woisky e Salatino, 1998; Frederice et al., 2010) Os extratos secos foram diluídos em EtOH para obter soluções com concentração de $10 \mathrm{mg} \cdot \mathrm{mL}^{-1}$. A uma alíquota de $0,2 \mathrm{~mL}$ desta solução foram adicionados $4,4 \mathrm{~mL}$ de $\mathrm{EtOH}$ e $0,4 \mathrm{~mL}$ de solução aquosa de $\mathrm{AlCl}_{3}$ a 2\%. Após 30 minutos, as absorvâncias das amostras foram medidas a $425 \mathrm{~nm}$.

Como referência, foi obtida uma curva analítica com a quercetina, que forneceu a equação da reta para a conversão da absorvância medida em miligramas equivalentes de quercetina por grama de extrato (mgEQ. $\left.g^{-1}\right)$.

\section{Avaliação da atividade antioxidante frente ao radical DPPH}


O radical estável 2,2-difenil-1-picril hidrazila (DPPH) tem sido amplamente utilizado para avaliar a capacidade de antioxidantes naturais em sequestrar radicais livres.

As substâncias antioxidantes presentes nos extratos reagem com o DPPH que é um radical estável, e converte-o em 2,2-difenil-1-picril hidrazina, com isso há uma mudança de cor do roxo para o amarelo. O grau de descoloração indica o potencial antioxidante do extrato (Mensor et al., 2001).

As soluções de trabalho foram preparadas a partir de diluições sucessivas dos extratos $(5,10,25$, 50,125 e $250 \mu \mathrm{g} \cdot \mathrm{mL}^{-1}$ ) em etanol, exceto o extrato IN que foi diluído em água. $\mathrm{O}$ ensaio foi realizado adicionando-se $2,5 \mathrm{~mL}$ de solução amostra a $1,0 \mathrm{~mL}$ de solução etanólica de DPPH $\left(2,99 \times 10^{-4} \mathrm{~mol}^{-\mathrm{L}^{-1}}\right)$. Um teste em branco, sem o DPPH, foi realizado em cada nível de concentração. Para o controle substituiu-se a amostra por etanol. As leituras de absorvância foram realizadas após 30 minutos em espectrofotômetro a $518 \mathrm{~nm}$. O cálculo da $C_{50}$ do padrão quercetina foi feita através da equação da reta obtida a partir do ensaio realizado nas concentrações de 1, 2, 4, 6, 8 e $10 \mu \mathrm{g} \cdot \mathrm{mL}^{-1}$.

A atividade antioxidante percentual (AA\%) em cada nível de concentração foi obtida a partir da equação: $A A \%=100-\{[(A b s$ amostra - Abs branco) $\times 100$ ] / Abs controle\}. Com esses valores, construíram-se curvas que relacionaram a $\mathrm{AA} \%$ $x$ concentração, a partir dos quais foi possível calcular, através de regressão logarítmica, o valor da concentração necessária para que a amostra exerça $50 \%$ de sua atividade antioxidante $\left(\mathrm{CE}_{50}\right)$.

\section{Análise por cromatografia em camada delgada (CCD)}

Os extratos foram submetidos à análise por CCD analítica em cromatofolha de alumínio (Merck Si-gel 60PF ${ }_{254+354}$ ), eluída no sistema AcOEt:MeOH:H2O (8,5:1,5:0,5), revelada sob luz visível com solução aquosa de $\mathrm{FeCl}_{3}$ a $1 \%$ e sob luz UV $365 \mathrm{~nm}$ com solução aquosa de $\mathrm{AlCl}_{3}$ a $1 \%$ em $\mathrm{MeOH}$.

\section{Análise cromatográfica por HPLC-DAD}

$\mathrm{O}$ extrato EA foi diluído em $\mathrm{MeOH}$ a uma concentração de $20 \mathrm{mg} \cdot \mathrm{mL}^{-1}$ e submetidos à análise por HPLC em coluna RP 18 Kromasil, $250 \mathrm{~mm} x$ $4,5 \mathrm{~mm}, 100 \AA$, volume de injeção de $20 \mu \mathrm{L}$, fluxo $1 \mathrm{~mL} \cdot \mathrm{min}^{-1}$. Como fase móvel utilizou-se o sistema $\mathrm{H}_{2} \mathrm{O}: \mathrm{H}_{3} \mathrm{PO}_{4}$ a $0,1 \%$ (A) e $\mathrm{MeOH}(\mathrm{B})$ na seguinte programação: $1-10$ min $(30 \% \mathrm{~B}), 20 \mathrm{~min}(40 \% \mathrm{~b})$, $60 \min (100 \%$ B), $80 \min (30 \%$ B), 81 min STOP. O $\mathrm{MeOH}$ utilizado foi em grau espectroscópico (TEDIA) e a água MilliQ.

\section{Análise estatística}

Todos os testes foram realizados em triplicata e os valores expressos como a média \pm desvio padrão. Com os resultados da atividade antioxidante frente ao radical DPPH, foi feita Análise de Variância (ANOVA) seguida do teste de Dunnett que comparou os valores de $\mathrm{CE}_{50}$ de cada extrato com o padrão quercetina, tomando-se o valor $p<$ 0,05 como nível máximo de significância, utilizandose o programa GraphPadPrism version 3.0.

\section{RESULTADO E DISCUSSÃO}

O teor de fenóis totais, o teor estimado de flavonoides totais e atividade antioxidante frente ao radical DPPH dos extratos EE, EH, ED, EA, EB, RA e IN são apresentados na Tabela 1. O extrato EA apresentou os maiores teores de fenóis e de flavonoides, 311,40 \pm 17,89 mgEAG.g ${ }^{-1}$ e 60,61 \pm 4,85 mgEQ. g $^{-1}$, respectivamente. Comparando-se a atividade antioxidante dos extratos testados com a do padrão quercetina pelo teste de Dunnet, o extrato EA apresentou a melhor atividade antioxidante, $C_{50} 15,0$ $\pm 0,5 \mu \mathrm{g} \cdot \mathrm{mL}^{-1}$. Paradoxalmente, a infusão apresentou teores de fenóis e de flavonoides superiores ao do extrato EB, mas sua atividade antioxidante frente ao radical DPPH foi inferior à atividade do extrato EB. Com base nessas evidências, não se pode afirmar que há uma relação direta entre a concentração de substâncias de natureza fenólica e flavonoídica presentes num extrato e sua atividade antioxidante frente ao radical DPPH. A relação entre estrutura química das moléculas presentes nos extratos e a atividade antioxidante apresentada deve ser considerada. A atividade antioxidante pode ter uma relação quantitativa com a presença de substâncias fenólicas, ou seja, a concentração das mesmas no extrato e/ou uma relação qualitativa relacionada à estrutura química destes derivados. $O$ número de hidroxilas livres presentes na molécula é uma característica importante para doar $\mathrm{H}$ e potencializar tal atividade.

A inspeção do perfil cromatográfico dos extratos EE, EH, ED, EA e EB por CCD analítica teve por objetivo observar a presença de substâncias de natureza fenólica e flavonoídica, principalmente nos extratos EH e ED cuja determinação do teor de flavonoides não foi realizada. Para esta prospecção, utilizou-se reveladores cromogênicos para fenóis, solução de $\mathrm{FeCl}_{3}$, e para flavonoides, solução de $\mathrm{AlCl}_{3}$ (Simões et al., 2001). A presença de fenóis foi observada pela utilização de $\mathrm{FeCl}_{3}$ sob luz visível, que produziu manchas de cor azul escuro, sendo o extrato EA, o que apresentou maior número de bandas. Com a utilização de solução de $\mathrm{AlCl}_{3}$ sob luz UV a $365 \mathrm{~nm}$, observou-se manchas verde azuladas fluorescentes em maior número de bandas nos extrato EE, EA e EB. 
TABELA 1. Teor de fenóis totais, teor estimado de flavonoides totais e atividade antioxidante frente ao radical DPPH dos extratos das folhas de Cordia verbenacea DC obtidos por maceração com posterior partição líquido/ líquido e infusão. Resultados expressos em termos de média \pm desvio padrão.

\begin{tabular}{llll}
\hline Extrat ${ }^{\mathrm{a}} \mathrm{a}$ & $\begin{array}{l}\text { Teor de fenóis totais } \\
\left(\mathrm{mgEAG} \cdot \mathrm{g}^{-1}\right)^{\mathrm{b}}\end{array}$ & $\begin{array}{l}\text { Teor de flavonoides totais } \\
\left(\mathrm{mgEQ} \cdot \mathrm{g}^{-1}\right)^{\mathrm{c}}\end{array}$ & $\begin{array}{l}\text { Atividade antioxidante } \\
\mathrm{CE}_{50}\left(\mu \mathrm{g} \cdot \mathrm{mL}^{-1}\right)\end{array}$ \\
\hline EE & $79,48 \pm 0,63$ & $65,03 \pm 4,59$ & $316,70 \pm 23,16$ \\
EH & $19,36 \pm 2,47$ & $\mathrm{na}^{\mathrm{d}}$ & $554,43 \pm 38,0$ \\
ED & $150,44 \pm 4,11$ & $\mathrm{na}^{\mathrm{d}}$ & $237,54 \pm 4,76$ \\
EA & $311,40 \pm 17,89$ & $60,61 \pm 4,85$ & $15,0 \pm 0,5$ \\
EB & $114,11 \pm 3,77$ & $11,98 \pm 1,25$ & $61,32 \pm 3,43$ \\
RA & $10,91 \pm 0,68$ & $1,29 \pm 0,56$ & $470 \pm 31,15$ \\
IN & $183,52 \pm 2,69$ & $24,68 \pm 4,65$ & $133,23 \pm 4,04$ \\
Quercetina & - & - & $2,33 \pm 0,14$ \\
\hline
\end{tabular}

aEE: extrato etanólico bruto, EH: extrato em hexano, ED: extrato em diclorometano, EA: extrato em acetato de etila, EB: extrato em n-butanol, RA: resíduo aquoso e IN: infusão.

${ }^{b}$ Expresso em equivalentes de ácido gálico $(\mathrm{mg})$ por grama de extrato.

'Expresso em equivalentes de quercetina $(\mathrm{mg})$ por grama de extrato.

${ }^{d}$ na: não avaliados devido à interferência das clorofilas.

${ }^{\text {e} A o s ~ r e s u l t a d o s ~ f o i ~ a p l i c a d o ~ o ~ T e s t e ~ d e ~ D u n n e t, ~}(p<0,05)$ onde EA e quercetina não apresentaram diferenças estatisticamente significativas.

Os compostos fenólicos em vegetais abrange uma gama de substâncias, desde moléculas simples até aquelas com alto grau de polimerização. Os ácidos fenólicos, como ácido cafeico, sináptico, ferúlico e gálico, possuem comprovada atividade antioxidante inibindo a peroxidação lipídica (Soares, 2002). A atividade antioxidante dos ácidos fenólicos e de polifenóis, como os flavonoides, está relacionada à habilidade dos mesmos em liberar homoliticamente o hidrogênio da ligação $\mathrm{O}-\mathrm{H}$ e formar radicais estáveis por efeito de ressonância ou por efeito de hiperconjugação. O padrão de hidroxilação e/ ou metoxilação influencia o potencial antioxidante destas moléculas (Quideau et al., 2011).

As referências bibliográficas consultadas, não apresentaram nenhuma análise por HPLC dos extratos com atividade antioxidante de $C$. verbenacea. Por esse motivo, buscou-se investigar o perfil das classes de metabólitos presentes no extrato com maior atividade antioxidante, EA, por HPLC-DAD. Como resposta analítica, obteve-se um número de picos cromatográficos superior ao número de bandas observáveis nos cromatogramas de CCD (Figura 1). Os picos de número 4, 5, 8, 23, 27, 31, 32 e 33 apresentaram máximos de absorção no ultravioleta que são mostrados na Tabela 2.

O pico $\mathrm{n}^{\circ} 4$ apresentou um máximo de absorção em $255 \mathrm{~nm}$, característico de grupo carbonila $\alpha, \beta$ insaturado. Num trabalho de Velde et al. (1982), o triterpeno cordialina A identificado em $C$. verbenacea, apresentou o mesmo máximo de absorção. $O$ pico $n^{\circ} 5$ apresentou máximos em 218, 234, 290 (ombro), $324 \mathrm{~nm}$, e perfil espectral semelhante a um fenilpropanoide como o ácido ferúlico, por exemplo (Chen et al., 2004). O pico $n^{\circ} 8$ apresentou máximos em 290 (ombro) e 329 nm que pode ser devido a um ácido fenólico com dois anéis aromáticos. O espectro de UV deste pico mostrouse muito semelhante ao do ácido rosmarínico encontrado em Borago officinalis L. (Wettasinghe et al., 2001). O ácido rosmarínico é um constituinte característico de espécies da família Lamiaceae e Boraginaceae, tendo sido apontado como um dos responsáveis pela atividade anti-inflamatória de Cordia americana (Geller et al., 2010) e de Cordia verbenacea (Ticli et al. 2005). Os picos de $n^{\circ} 23$, 27, 31, 32 e 33 apresentaram máximos de absorção entre $255-272 \mathrm{~nm}$ e 338-353 nm, onde 27, 31 e 32 apresentaram ombro em $271 \mathrm{~nm}$. A absorção nestas regiões do espectro de UV pode estar relacionada a derivados flavônicos (240-285 - banda II e 300-400 nm - banda I) de núcleo benzopirona (Simões et al., 2001). No espectro do pico $n^{\circ} 23$, o pico de máximo em $346 \mathrm{~nm}$ apresentou-se menos intenso que o de máximo em $259 \mathrm{~nm}$ podendo ser um indicativo da presença de isoflavona. Um considerável número de flavonoides foi relatado

TABELA 2. Picos cromatográficos mais intensos observados no cromatograma obtido por HPLCDAD e seus respectivos máximos de absorção nos espectros de UV.

\begin{tabular}{ll}
\hline Pico $\left(\mathrm{n}^{\circ}\right)$ & $\lambda_{\text {máx }}(\mathrm{nm})$ \\
\hline 4 & 255 \\
5 & $218,234,290$ (ombro), 324 \\
8 & 290 (ombro), 329 \\
23 & 259,347 \\
27 & 257,271 (ombro), 350 \\
31 & 256,271 (ombro), 347 \\
32 & 255,271 (ombro), 353 \\
33 & 272,338 \\
\hline
\end{tabular}



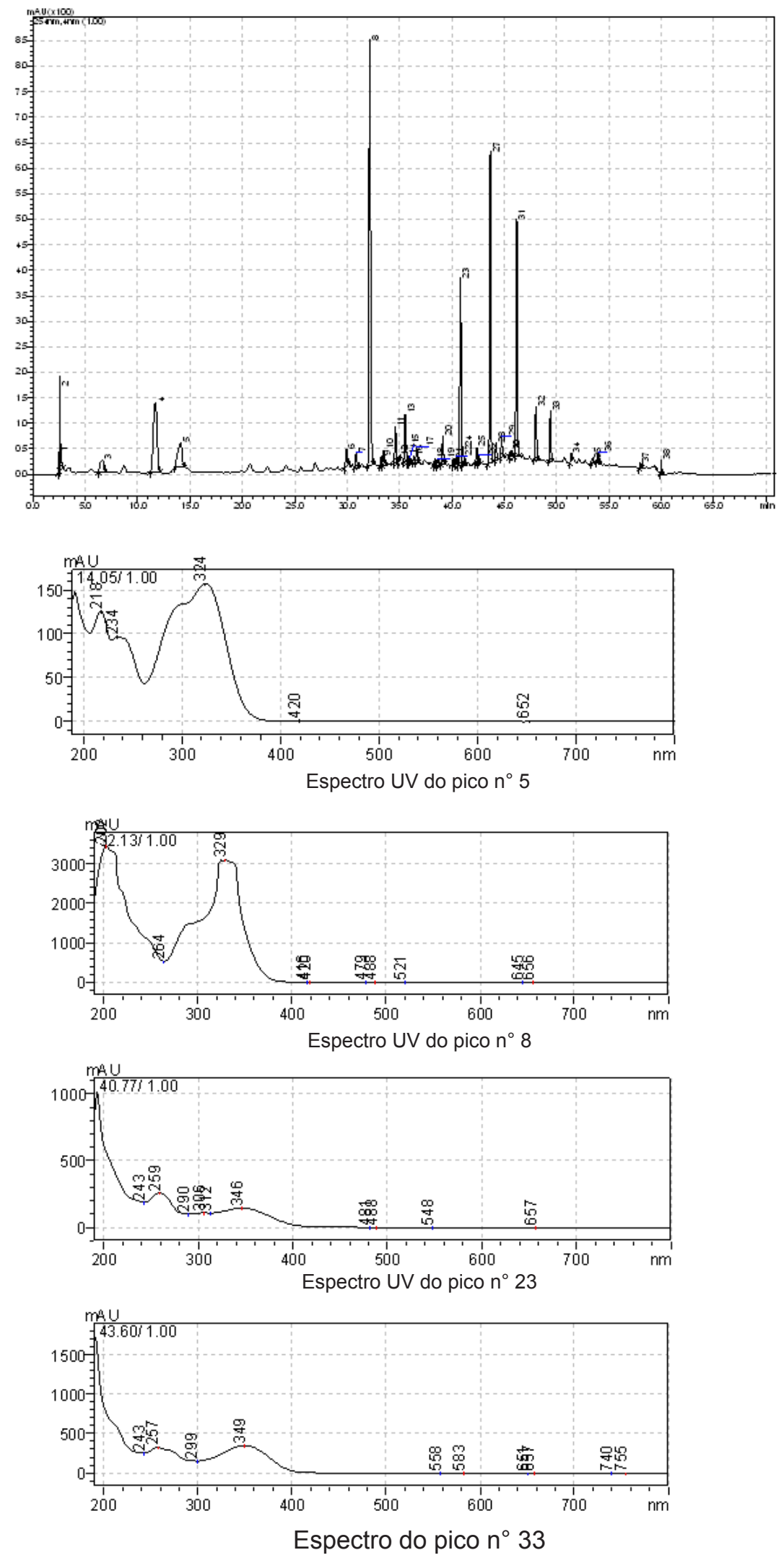

FIGURA 1. Cromatograma obtido por HPLC-DAD do extrato EA de Cordia verbenacea em $254 \mathrm{~nm}$ e espectros de UV dos picos 5, 8, 23, e 27. 
em espécies de Boraginaceae por Wollenweber el al. (2002). Em Cordia verbenacea, duas flavonas (5,6'-diidroxi-3,6,7, 3', 4'-pentametoxiflavona e 5- hidroxi-3,6,7,3',4'-pentametoxiflavona) e duas isoflavonas (7,4'-diidroxi-5'-carbometóxi isoflavona e 7,4'-diidroxi-5'-metil isoflavona) já foram identificadas (Velde et al. 1982; Ameira et al., 2009). À classe dos flavonoides têm sido atribuídas diversas atividades biológicas, tais como atividade antioxidante e anti-inflamatória, tendo nestes casos forte relação estrutura-atividade (Coutinho et al., 2009).

\section{CONCLUSÃO}

Com base nos resultados obtidos pode-se concluir que dentre os extratos das folhas de Cordia verbenacea, o extrato EA apresentou a melhor atividade antioxidante frente ao radical DPPH. Este extrato também apresentou os mais altos teores de fenóis e de flavonoides. Entretanto, em relação aos demais extratos testados, não se observou uma relação direta entre a concentração de fenóis e de flavonoides e a atividade antioxidante frente ao radical DPPH. Tal atividade é, portanto, influenciada por fatores qualitativos e não somente quantitativos no que se refere à composição dos extratos. Através da análise do extrato EA por HPLC-DAD e dados da literatura foi possível observar a existência de compostos cujos perfis de UV corroboram o potencial antioxidante do mesmo. Os resultados obtidos no presente trabalho sugerem uma investigação da atividade antiúlcera do extrato EA bem como a identificação de seus componentes através de técnicas cromatográficas e espectroscópicas complementares.

\section{AGRADECIMENTO}

À Fundação Carlos Chagas Filho de Amparo à Pesquisa do Estado do Rio de Janeiro (FAPERJ) pela bolsa de Iniciação Científica concedida.

\section{REFERÊNCIA}

AMEIRA, O.A. et al. Estabelecimento de cultura de células em suspensão e identificação de flavonoides em Cordia verbenacea DC. Revista Brasileira de Plantas Medicinais, v. 11, n. 1, p. 7-11, 2009.

CHEN, X. et al. Separation and identification of compounds in Rhizoma chuanxiong by comprehensive twodimensional liquid chromatography coupled to mass spectrometry. Journal of Chromatography A, v. 1040, n. 2, p. 169-178, 2004.

COUTINHO, M.A.S.; MUZITANO, A.S.; COSTA, S.S. Flavonoides: potenciais agentes terapêuticos para o processo inflamatório. Revista Virtual de Química, v. 1, n. 3, p. 241-256, 2009. Disponível em: <http://www. uff.br/rvq>. Acesso em: 20 de março de 2012.

DOWLD, L.E. Spectrophotometric determination of quercetin. Analytical Chemistry, v. 31, n. 7, p.11841187, 1959.

FREDERICE, R.; FERREIRA, A.P.G.; GEHLEN, M.H. Molecular Fluoręscence in Silica Particles Doped with Quercetin-Al Complexes. Journal of Brazilian Chemical Society, v. 21, n. 7, p. 1213-1217, 2010.

GELLER, F. et al. Identification of rosmarinic acid as the major active constituent in Cordia americana. Journal of Ethnopharmacology, v.128, n. 3, p. 561-566, 2010.

LORENZI, H.; MATOS, F.J.A. Plantas medicinais no Brasil nativas e exóticas. $2^{a}$ edição. Nova Odessa, SP: Instituto Plantarum, 2008. 544p.

LUGASI, A. et al. Antioxidant and free radical scavenging properties of squeezed juice from blackradish (Raphanus sativus L. var niger) root. Phytotheraphy Research, v.12, n. 7, p. 502-506, 1998.

MENSOR, L.L. et al. Screening of Brazilian plant extracts for antioxidant activity by use of DPPH free radical method. Phytotheraphy Research, v.15, n. 2, p.127130, 2001.

MICHIELIN, E.M.Z. et al. Radical scavenging activity of extracts from Cordia verbenacea DC obtained by different methods. The Journal of Supercritical Fluids, v. 56, n. 1, p. 89-96, 2011.

OLIVEIRA, A.C. et al. Fontes vegetais naturais de antioxidantes. Química Nova, v. 32, n. 3, p. 689-702, 2009.

QUIDEAU, S. et al. Plant polyphenols: chemical properties, biological activities and synthesis. Angewandte Chemie International Edition, v. 50, n. 3, p. 586-621, 2011.

ROLDÃO, E.F. et al., Evaluation of the antiulcerogenic and analgesic activities of

Cordia verbenacea DC. (Boraginaceae). Journal of Ethnopharmacology, v. 119, n. 1, p. 94-98, 2008.

SANTI, M.M. et al. Microwave-assisted extraction from Cordia verbenace leaves: comparison with conventional maceration methods. In: SIMPÓSIO IBEROAMERICANO DE PLANTAS MEDICINAIS, 5, 2010, Itajaí. Resumo em anais de evento (CD ROM). Itajaí: UNIVALI, 2010.

SIMÕES, C.M.O. et al. Farmacognosia da planta ao medicamento. $2^{a}$ edição. Porto Alegre/Florianópolis, SC: Ed. Universidade /UFRGS/Ed. Da UFSC, 2000. 821p.

SOARES, S.E. Ácidos fenólicos como antioxidantes. Revista de Nutrição, v. 15, n. 1, p. 71-81, 2002.

TICLI, F.K. et al. Rosmarinic acid, a new snake venom phospholipase $A_{2}$ inhibitor from Cordia verbenacea (Boraginaceae): antiserum action potentiation and molecular interaction. Toxicon, v. 46, n. 3, p. 318-327, 2005.

VELDE, V.V. et al. Cordialin A and B, two new triterpenes from Cordia verbenacea DC. Journal of Chemical Society, Perkin Transactions 1, p. 2697-2700, 1982.

WETTASINGHE, M. et al. Phenolic acids in defatted seeds of borage (Borago officinalis L.). Food Chemistry, v. 75, n. 1, p. 49-56, 2001.

WOISKI, R.G.; SLATINO, A. Analysis of propolis: some parameters and procedures for chemical quality control. Journal of Apicultural Research, v. 37, n. 2, p. 99-105, 1998.

WOLLENWEBER, E. et al. On the occurrence of exudate flavonoids in the borage family (Boraginaceae). Zeitschrift für Naturforschung C, v. 57, n. 5-6, p. 445-448, 2002. 